\title{
How much energy storage can we afford? On the need for a sunflower society, aligning demand with renewable supply
}

\author{
Harald Desing*1, Rolf Widmer ${ }^{1}$ \\ 1 Empa - Swiss Federal Laboratories for Material Science and Technology, Lerchenfeldstrasse \\ 5, 9014 St. Gallen, Switzerland \\ * corresponding author: harald.desing@empa.ch
}

Our society has become accustomed to demanding energy whenever we want it. When decarbonising the energy system, this becomes a fundamental challenge due to the extent of energy storage required for matching the intermittent renewable supply to society's current demand. Available energy storage technologies are energetically expensive either to build - like batteries - or to operate - like synthetic fuels. Due to these energetic costs, requiring more storage leads to a slower energy transition and consequently higher climate risks. This paper explores the energy implications of adding energy storage to fast and complete energy transition pathways. Technological innovation can mitigate the problem to some extent by focusing on reduced energy intensity of storage alongside with improved turnaround efficiency. Most influential is, however, the extent of storage that we want: reducing storage demand greatly accelerates the transition and therefore reduces the induced probability of violating $1.5^{\circ} \mathrm{C}$ peak heating. In addition, it can immediately be implemented with readily available and scalable technologies. However, it requires a fundamental rethinking of the way we use energy in society: aligning energy demand with renewable supply as best as we can. Following the course of the sun, just like sunflowers do, we need to schedule our most energy-intensive activities around midday and summer, while reducing demand during night and winter. The sunflower society has the potential to accelerate climate action and therewith reduce climate risks.

With the climate crisis unfolding, the urgency for climate action is coming to the fore and the rapid energy transition is inevitable. However, most proposed energy transition pathways exceed $1.5^{\circ} \mathrm{C}$ peak heating, which is considered a safe threshold [1-3], with a chance of $>40 \%$ [3, 4]. The fastest possible energy transition - i.e. a complete replacement of the current fossil with a solar energy supply system [5] constrained only by energy [4] - can at best reduce the probability of violating the $1.5^{\circ} \mathrm{C}$ limit to $20 \%$ [4]. Adding energy storage to the equation will increase climate risks, as the additional energy necessary to build and operate this storage will delay the transition. This paper explores the implications of energy storage on fast and complete energy transitions when only considering energy constraints.

Energy storage options Many different technologies to store energy are in use or under development [6, 7]. They differ in the physical principles, in energetic performance and resource demand. Here, the focus is 
on the turnaround efficiency $\eta_{\text {turnaround }}$, characterizing the energy losses during operation, and the energy intensity $E I$, describing the energy required to build storage capacity. While the former is commonly reported and target for improvements [6, 7], few studies even report the embodied energy for storage technologies (e.g. [8-10]). Knowing the energy "cost" to build storage capacity is, however, fundamental for modelling the transition based on energy balances. In this paper, we estimate the energy intensity, defined as embodied energy per storage capacity (Section S2, Equation 1), for three exemplary storage technologies based on life cycle inventories in literature: Li-ion batteries [11], pumped hydro storage [12] and synthetic methane [13] (Section S2). A comprehensive review for quantifying the energy intensity of other storage technologies is a potential area of future research.

Li-ion batteries are the leading storage technology for mobile applications, from smartphones to electric vehicles. Various chemistries exist and are under development, which contain different amounts of Li and other metals, such as $\mathrm{Co}, \mathrm{Cu}, \mathrm{Mn}, \mathrm{Ni}$ or $\mathrm{Al}$. Li and $\mathrm{Co}$, are currently the main drivers for embodied energy of Li-ion batteries [11]. While Li-ion batteries have a high turnaround efficiency $\eta_{\text {turnaround,Li-ion }}=0.85$, they have a high energy intensity $E I_{\mathrm{Li}-\text { ion }} \approx 400$ (i. e. embodied energy is approximately 400 times nominal storage capacity, Section S2).

Pumped hydro storage (PHS) is a well established technology and today the only mechanical storage employed at large scale. It has a turnaround efficiency of about $\eta_{\text {turnaround,PHS }}=0.7[7,9,12,14]$ and energy intensity of $E I_{\mathrm{PHS}} \approx 80$ (Section S2). Suitable sites for traditional pump hydro storage are not available in all locations and there is increasing opposition to new large scale hydro power projects. However, technologies are in development that can be installed also on flat land [15, 16] and may imply a similar energy intensity, as it requires same equipment along with dam construction and tunnelling. Other mechanical energy storage technologies may become available at scale, such as flywheels, compressed air energy storage or gravity storage with solids [6].

Synthetic methane, produced with hydrogen from electrolysis of water and methanization with carbon from direct air capture (DAC) to $\mathrm{CH}_{4}$ [13], is taken as the example for chemical storage technologies. It can be easily stored and used in existing infrastructures (e.g. internal combustion engines, gas turbines, domestic heating systems). Like all chemical storage technologies [17], synthetic methane has a low turnaround efficiency $\left(\eta_{\text {turnaround, }} \mathrm{CH}_{4}=0.16[13]\right)$ and is therefore energetically expensive to operate. However, it has the lowest energy intensity $E I_{\mathrm{CH}_{4}} \approx 60$ (Section S2). Other synthetic fuels may have higher efficiency (e.g. $\mathrm{H}_{2}$, which is, however, difficult to store, $\eta_{\text {turnaround, } \mathrm{H}_{2}} \approx 0.3$ [18]) or even lower efficiency (e.g. $\mathrm{CH}_{3} \mathrm{OH}$ if burned in an internal combustion engine $\eta_{\text {turnaround, } \mathrm{CH}_{3} \mathrm{OH} \text { in ICE }} \approx 0.09$ [17]) .

Other forms of storage, such as thermal storage in phase change materials or electro-magnetic storage such as supercapacitors and superconductors, are still in their development for large scale applications and not considered here for simplicity.

Storage demand It is apparent that there are some uses of energy, which have to take place when the main renewable resource - direct conversion of insolation to electricity [5] - is not available. E. g. artificial light is required when it is dark outside. Most other energy uses can be scheduled more or less freely throughout the day.

Assuming a constant average demand over the course of a day, there is a need to store $\phi_{\mathrm{d}, \max }=0.58$ of the daily energy demand. As energy demand is generally higher during the day, this can be considered the upper limit of daily storage requirements (see Section S3). Electricity use patterns [19] show globally somewhat less storage demand $\phi_{\mathrm{d} \text {, global }}=0.54$ in 2015 (Fig. S4). Leveling demand profiles is beneficial for thermal power plant operations. That is why in many regions electricity tariffs are lower during the night, providing an incentive to shift energy demand into the night. However, keeping up this demand patterns creates a fundamental challenge for the transition to a solar powered society, as solar supply is by its very nature only available during the day. The country with the demand pattern best aligned to solar supply is Mozambique (Fig. S4), however it still has a daily storage demand of $\phi_{\mathrm{d}, \mathrm{MOZ}}=0.45$.

For annual storage an additional $\phi_{\mathrm{a}, \max }=0.2$ has to be stored to level out beyond daily variations (periods of cloud cover, annual variations in higher latitudes). Consequently, the fraction of daily average demand, which needs to be provided through storage, will lie in between $\phi=[0,0.8]$.

Besides the fraction of energy needing storage, there is also the size of the storage capacity to consider. If only daily storage is required, an independence time of $\Delta t_{i}=14.5 \mathrm{~h}=0.0017 \mathrm{a}$ (Section S3) will be sufficient. Cloudy and windless periods increase the demand for storage capacity up to the order of days, whereas seasonal variations of solar (and renewable) availability increase the demand up to months. However, as most of the world's population is currently living around the equator ("sun belt") where 
seasonal variations are low [20], the global need for storage capacity will likely not be beyond $\Delta t_{i}<0.1$ a.

Influence of storage on transition Adding energy storage to fast and complete energy transition pathways [4], has two main effects on the energy system (Fig. 1): (I) energy for building storage capacity needs to be provided in addition, necessarily slowing down the build-up of solar capacity. And (II) the solar output needs to be able to provide for storage losses, therefore increasing the required solar capacity. Both requirements are slowing down the transition and potentially increase the cumulative fossil carbon emissions.

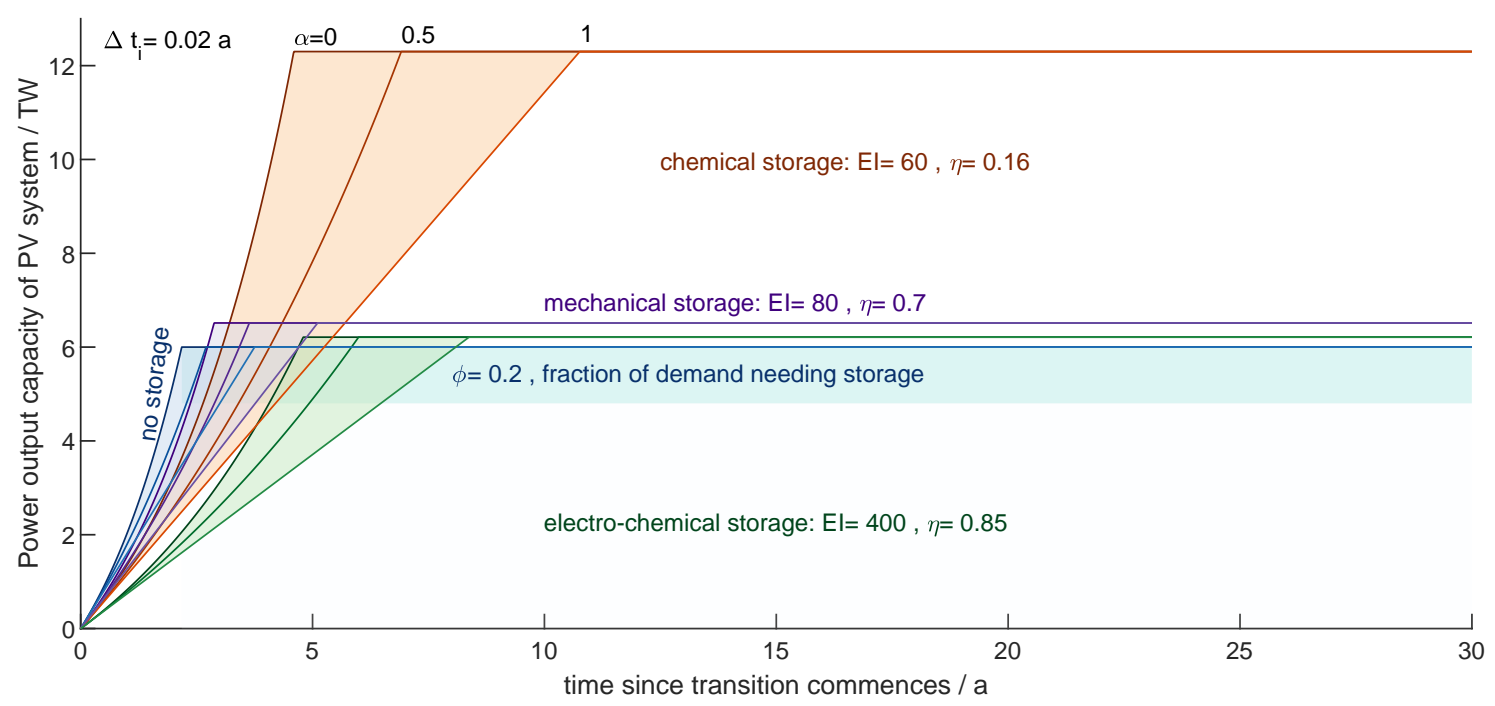

Figure 1: Transition dynamic for $\phi=0.2$ and $\Delta t_{i}=0.02 \mathrm{a}$ (which is approximately one week). Transition without storage [4] in blue, chemical storage (orange), mechanical storage (violet) and electrochemical storage (green). Fossil replacement factor $\alpha=0$ allows an exponential and therefore fastest growth, whereas $\alpha=1$ leads to a linear growth.

Larger storage capacities - desribed by independence time $\Delta t_{i}$ - slow down the growth of the solar engine; whereas increasing storage throughput $(\phi)$ necessitates to build the solar engine larger in order to compensate for increased storage losses (Fig. S1). The former effect is most pronounced for storage technologies with high energy intensity (e.g. electro-chemical storage), while the latter is most influential for storage technologies with low turnaround efficiency (e.g. chemical storage).

Increasing storage demand raises the probability to violate both $1.5^{\circ} \mathrm{C}$ and $2{ }^{\circ} \mathrm{C}$ substantially above a transition without storage (Fig. S2). Energy intensity of storage is most influential on the speed of the transition. Even though chemical storage has a low turnaround efficiency, it comes at low embodied energy, enabling a fast transition. Increasing storage capacity (independence time, see Fig. 2) has a comparatively smaller effect than increasing storage fraction $\phi$. In contrast, electro-chemical storage technologies typically have high turnaround efficiencies, but also a high energy intensity. Increasing the storage fraction has a much smaller effect than increasing storage capacity ${ }^{1}$.

Implications Increasing storage capacity and throughput also increases the probability to violate $1.5^{\circ} \mathrm{C}$ heating (Fig. 2 and S2). Pumped hydro storage (as a representative technology for mechanical storage) increases climate risks the least, as it has both a relatively low energy intensity and high turnaround efficiency. However, suitable topological sites are rare and new technologies independent of topography are still in their infancy, which makes PHS difficult to scale for the moment. Li-ion batteries are a good

\footnotetext{
${ }^{1}$ Note, the effect of changing storage fraction and storage capacity on the lifetime, and therefore replacement needs, is not considered as for most fast transitions replacements will not be necessary during the transition. For modelling the behaviour of the system after the transition, EoL replacements need to be considered, which is a potential area for further research.
} 


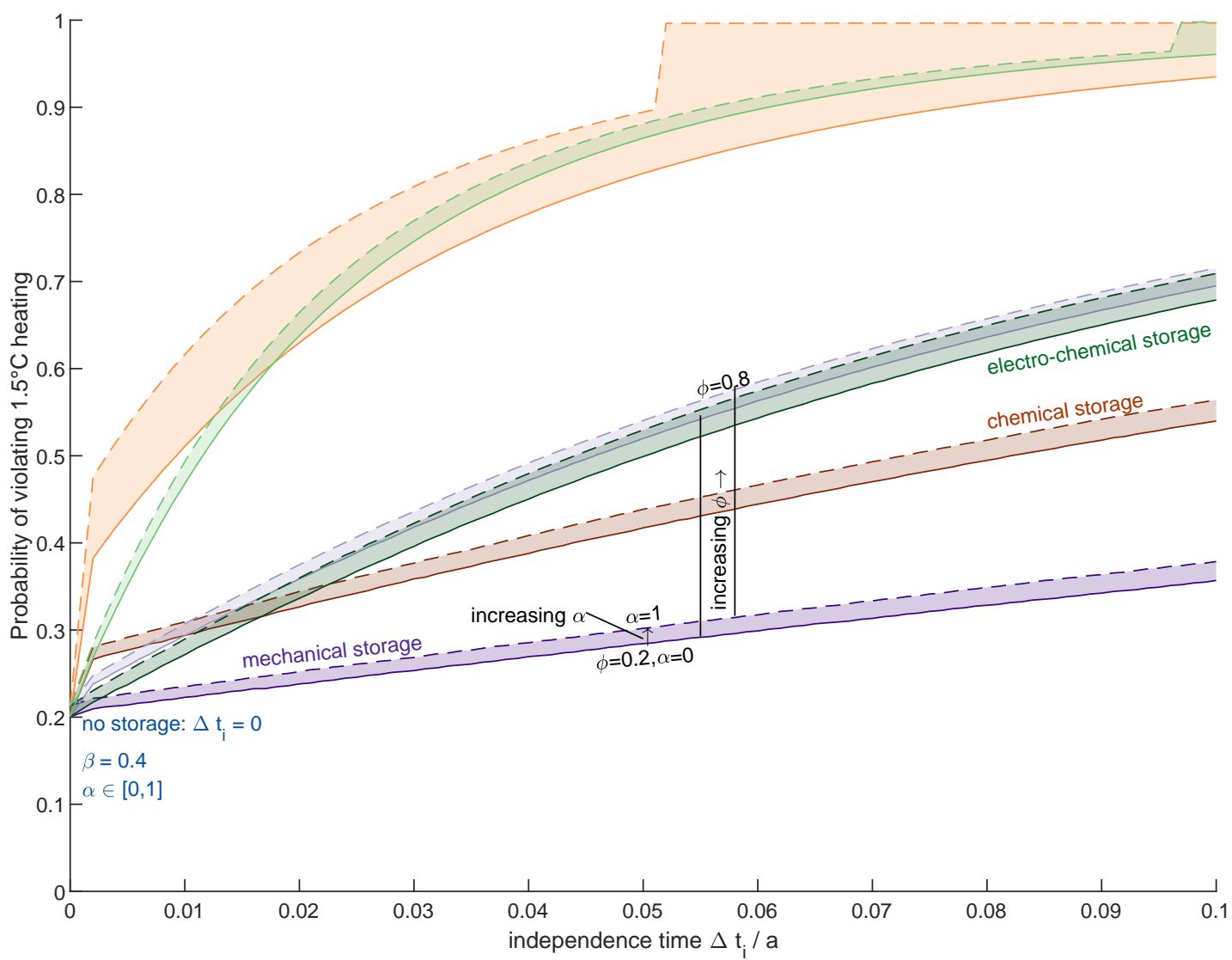

Figure 2: Probability of violating $1.5^{\circ} \mathrm{C}$ as a function of independence time $\Delta t_{i}$. Blue line indicates the probabilities and transition times for a transition without storage [4]. Both transition time and probability of violation increase with $\phi$ and $\Delta t_{i}$, however, depending on storage technology groups differently: mechanical storage (violet), chemical storage (orange) and electro-chemical storage (green).

option for very small independence times of about a day or two $\left(\Delta t_{i}<0.005\right)$, whereas synthetic methane can at best be useful as long-term, seasonal storage with low throughput.

Research and development into novel storage technologies need to focus on reducing energy intensity while increasing turnaround efficiency. However, time is pressing, as every year of climate inaction increases cumulative emissions by about $42 \mathrm{Gt}[4,21,22]$, increasing the probability to exceed $1.5^{\circ} \mathrm{C}$ heating by $5 \%$ (percentage points) every year. Consequently, the transition needs to commence immediately with readily available and scalable technologies. New storage technologies can, once market ready, allow to increase storage capacity and throughput in the future.

The second possibility to reduce climate risks is to reduce the demand for storage, both in terms of independence time and fraction of demand needing storage. This, however, requires a fundamental re-thinking of the way we use energy in society.

Sunflower society Following the course of the sun, just like sunflowers do, we as society can schedule our most energy intensive activities around midday and summer, while reducing the demand at night and in winter to its bare minimum. Aligning energy demand with solar supply can greatly reduce the demand for storage (Fig. 3). This is not an Utopian scenario, in contrary: it had been the rule throughout most of humanity's and life's history. For instance, plants are most active during peak sun hours and in summer, while dormant in the night and during winter. And consequently, agricultural societies had been following the activity cycles of plants. Also, an industrial society can, in principle, operate in the rhythm of the sun.

Implementing a sunflower society requires a paradigm shift in society. In the following, we will outline 


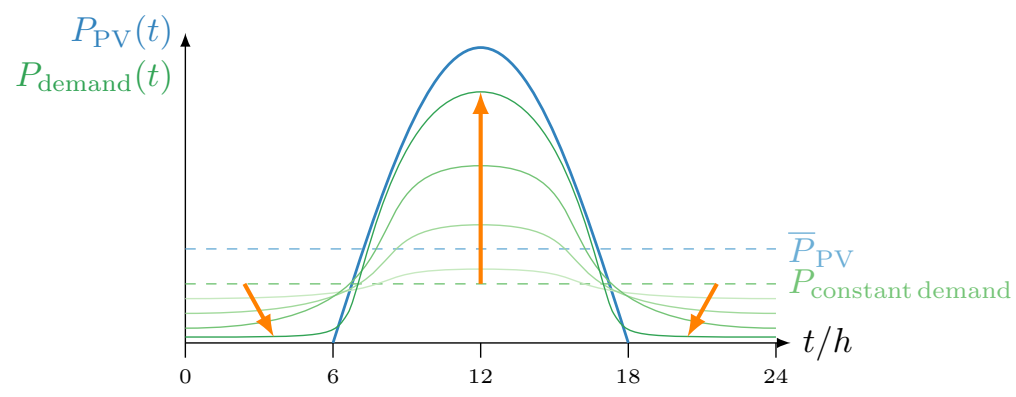

Figure 3: Sunflower society aligns (orange arrows) the demand (green lines) with renewable supply (blue line) throughout the course of a day.

founding principles for such a change.

Avoided energy demand also avoids storing it. Therefore, energy efficiency and energy sufficiency [23, $24]$ are the basis for the sunflower society. This is especially the case for energy uses that cannot be shifted, e. g. lighting. Here it is most important to apply and evolve as-efficient-as-possible technologies and use it only when absolutely necessary. Reducing lighting has the additional benefit of avoiding light pollution obstructing wildlife. In addition, it is also particularly important for any energy intensive process. For example, reducing the demand for aluminium and shifting from primary production to increased recycling, has the potential to significantly reduce both energy demand and the pressure on limited resources [25].

The need for daily storage can be reduced by concentrating energy demand around peak sun hours across all demand areas. Technologies can support and enable the alignment of demand with supply. For example, through the shift away from continuously operating technologies - like steel making in blast furnaces - to batch operations during peak sun hours - like it will be possible for hydrogen steel making in electric arc furnaces [26]. Even processes that are designed for continuous operations, like blast furnaces, can - in principle - use their thermal inertia to reduce energy demand throughout the night. This alignment can be stimulated through hourly energy tariffs which are lower during peak sun hours. This is simply inverting today's practice of providing incentives for using energy during the night.

It further means to change behavioural patterns - like reducing mobility demand and shifting to grid-connected modes of transport. For example, charging battery electric vehicles during the night would require double storage: one for storing solar energy harvested during the day and one in the car, which is charged in the night. Grid-connected modes of transport, like trolleybuses and trains, can provide the same transport service during the day without any storage.

Demand for storage beyond daily variation should ideally be avoided completely. Space heating, for example, is necessary during the coldest months, when insolation is lowest. Space heating demand can be reduced by reducing the floor space per inhabitant or building multi-family houses, which have a smaller surface-to-volume ratio. Or it can be avoided completed by upgrading existing houses into passive houses. The embodied energy in materials (e.g. insulation, thermal mass) can shift active demand for heating to passive demand in materials.

Over-sizing solar capacity can contribute to avoiding seasonal storage altogether. As the energy intensity of solar PV systems is much lower than for energy storage, it is energetically cheaper to build. PV systems can be oversized in order to provide the daily demand also on the day of the year with lowest insolation. During the rest of the year, excess power can be either curtailed or used to power the next big human endeavour after the energy transition: cleaning up the atmosphere. Excess $\mathrm{CO}_{2}$ in the atmosphere can be removed with direct air capture and storage technologies [27-30] and stored permanently, thus reverting anthropogenic climate heating and stabilizing the climate in the long run.

In addition, there is the option to transport energy via electric energy grids. Efficient long distance energy transmission is rapidly expanding [31] and will gain importance to minimize storage needs by levelling regional insolation differences, e. g. due to local cloud cover. It can further transport energy for early evening demand from West to East. The energy requirements and implications on the transition remains to be investigated.

Conclusion Averting the climate crisis requires fast, deliberate and coordinated climate action, above all the complete phase out of fossil fuels. As shown here, keeping up today's energy demand patterns requires 


\section{References}

1. Lenton, T. M., Rockstrom, J., Gaffney, O., Rahmstorf, S., Richardson, K., Steffen, W. \& Schellnhuber, H. J. Climate tipping points - too risky to bet against. Nature 575, 592-595. www. doi .org/10. 1038/d41586-019-03595-0 (2019).

2. Hoegh-Guldberg, O., Jacob, D., Taylor, M., Guillen Bolanos, T., Bindi, M., Brown, S., Camilloni, I. A., Diedhiou, A., Djalante, R., Ebi, K., Engelbrecht, F., Guiot, J., Hijioka, Y., Mehrotra, S., Hope, C. W., Payne, A. J., Portner, H. O., Seneviratne, S. I., Thomas, A., Warren, R. \& Zhou, G. The human imperative of stabilizing global climate change at 1.5 degrees C. Science 365, 1-11. www.doi.org/10.1126/science. aaw6974 (2019).

3. IPCC. Global Warming of 1.5 degree C. An IPCC Special Report on the impacts of global warming of 1.5 degree $C$ above pre-industrial levels and related global greenhouse gas emission pathways, in the context of strengthening the global response to the threat of climate change, sustainable development, and efforts to eradicate poverty Report (Intergovernmental Panel for Climate Change, 2018).

4. Desing, H. \& Widmer, R. Reducing climate risks with fast and complete energy transitions: applying the precautionary principle to the Paris agreement. Environmental Research Letters. www.doi.org/ 10.31219/osf.io/5wf64 (submitted).

5. Desing, H., Widmer, R., Beloin-Saint-Pierre, D., Hischier, R. \& Wäger, P. Powering a Sustainable and Circular Economy-An Engineering Approach to Estimating Renewable Energy Potentials within Earth System Boundaries. Energies 12, 1-18. www.doi.org/10.3390/en12244723 (2019).

6. Letcher, T. Storing Energy - with special reference to renewable energy sources www.doi.org/10. 1016/b978-0-12-803440-8.00026-9 (Elsevier, The Netherlands, 2016).

7. Koohi-Fayegh, S. \& Rosen, M. A. A review of energy storage types, applications and recent developments. Journal of Energy Storage 27. www.doi.org/10.1016/j.est.2019.101047 (2020).

8. Argonne National Laboratory. A Review of Battery Life-Cycle Analysis: State of Knowledge and Critical Needs Report (2010). http://www.osti.gov/bridge.

9. Barnhart, C. J. \& Benson, S. M. On the importance of reducing the energetic and material demands of electrical energy storage. Energy and Environmental Science 6. www.doi.org/10.1039/c3ee24040a (2013).

10. Barnhart, C. J., Dale, M., Brandt, A. R. \& Benson, S. M. The energetic implications of curtailing versus storing solar- and wind-generated electricity. Energy and Environmental Science 6. www.doi. org/10.1039/c3ee41973h (2013).

11. Crenna, E., Gauch, M., Widmer, R., Wäger, P. \& Hischier, R. Towards more flexibility and transparency in life cycle inventories for Lithium-ion batteries. Resources, Conservation and Recycling 170. www.doi.org/10.1016/j.resconrec.2021.105619 (2021).

12. Wernet, G., Bauer, C., Steubing, B., Reinhard, J., Moreno-Ruiz, E. \& Weidema, B. The ecoinvent database version 3 (part I): overview and methodology. The International Journal of Life Cycle Assessment 21, 1218-1230. www.doi.org/10.1007/s11367-016-1087-8 (2016).

13. Zhang, X., Bauer, C., Mutel, C. L. \& Volkart, K. Life Cycle Assessment of Power-to-Gas: Approaches, system variations and their environmental implications. Applied Energy 190, 326-338. www. doi . org/10.1016/j . apenergy . 2016.12.098 (2017).

14. Bauer, C., Bolliger, R., Tuchschmid, M. \& Faist-Emmenegger, M. in Sachbilanzen von Energiesystemen: Grundlagen für den ökologischen Vergleich von Energiesystemen und den Einbezug von Energiesystemen in Ökobilanzen für die Schweiz (ed Dones, R.) (Paul Scherer Institut, Swiss center for life cycle inventories, Dübendorf, Switzerland, 2007). 
15. Heindl, E. Hydraulic Hydro Storage System for Self-sufficient Cities. Energy Procedia 46, 98-103. www.doi.org/10.1016/j.egypro.2014.01.162 (2014).

16. Heindl, E. Gravity storage Web Page. 2021. https://heindl-energy.com/.

17. Alten, S., Rihko-Struckmann, L., Hanke-Rauschenbach, R. \& Sundmacher, K. Chemische Speicherung regenerativ erzeugter Energie durch Reduktion von CO2 zu flüssigen Kraftstoffen Report (Max Plank Institut für Dynamik komplexer technischer Systeme, 2021).

18. Pellow, M. A., Emmott, C. J. M., Barnhart, C. J. \& Benson, S. M. Hydrogen or batteries for grid storage? A net energy analysis. Energy and Environmental Science 8, 1938-1952. www.doi .org/10. 1039/c4ee04041d (2015).

19. Brinkerink, M., Gallachóir, B. Ó. \& Deane, P. Building and Calibrating a Country-Level Detailed Global Electricity Model Based on Public Data. Energy Strategy Reviews 33. www.doi.org/10. 1016/j.esr.2020.100592 (2021).

20. Victoria, M., Haegel, N., Peters, I. M., Sinton, R., Jäger-Waldau, A., del Cañizo, C., Breyer, C., Stocks, M., Blakers, A., Kaizuka, I., Komoto, K. \& Smets, A. Solar photovoltaics is ready to power a sustainable future. Joule 5, 1041-1056. www.doi.org/10.1016/j.joule.2021.03.005 (2021).

21. Friedlingstein, P., Jones, M. W., O’Sullivan, M., Andrew, R. M., Hauck, J., Peters, G. P., Peters, W., Pongratz, J., Sitch, S., Le Quéré, C., Bakker, D. C. E., Canadell, J. G., Ciais, P., Jackson, R. B., Anthoni, P., Barbero, L., Bastos, A., Bastrikov, V., Becker, M., Bopp, L., Buitenhuis, E., Chandra, N., Chevallier, F., Chini, L. P., Currie, K. I., Feely, R. A., Gehlen, M., Gilfillan, D., Gkritzalis, T., Goll, D. S., Gruber, N., Gutekunst, S., Harris, I., Haverd, V., Houghton, R. A., Hurtt, G., Ilyina, T., Jain, A. K., Joetzjer, E., Kaplan, J. O., Kato, E., Klein Goldewijk, K., Korsbakken, J. I., Landschützer, P., Lauvset, S. K., Lefèvre, N., Lenton, A., Lienert, S., Lombardozzi, D., Marland, G., McGuire, P. C., Melton, J. R., Metzl, N., Munro, D. R., Nabel, J. E. M. S., Nakaoka, S.-I., Neill, C., Omar, A. M., Ono, T., Peregon, A., Pierrot, D., Poulter, B., Rehder, G., Resplandy, L., Robertson, E., Rödenbeck, C., Séférian, R., Schwinger, J., Smith, N., Tans, P. P., Tian, H., Tilbrook, B., Tubiello, F. N., van der Werf, G. R., Wiltshire, A. J. \& Zaehle, S. Global Carbon Budget 2019. Earth System Science Data 11, 1783-1838. www.doi.org/10.5194/essd-11-1783-2019 (2019).

22. Le Quéré, C., Jackson, R. B., Jones, M. W., Smith, A. J. P., Abernethy, S., Andrew, R. M., De-Gol, A. J., Willis, D. R., Shan, Y., Canadell, J. G., Friedlingstein, P., Creutzig, F. \& Peters, G. P. Temporary reduction in daily global CO2 emissions during the COVID-19 forced confinement. Nature Climate Change 10, 647-653. www.doi.org/10.1038/s41558-020-0797-x (2020).

23. Millward-Hopkins, J., Steinberger, J. K., Rao, N. D. \& Oswald, Y. Providing decent living with minimum energy: A global scenario. Global Environmental Change 65. www.doi.org/10.1016/j . gloenvcha.2020.102168 (2020).

24. Grubler, A., Wilson, C., Bento, N., Boza-Kiss, B., Krey, V., McCollum, D. L., Rao, N. D., Riahi, K., Rogelj, J., De Stercke, S., Cullen, J., Frank, S., Fricko, O., Guo, F., Gidden, M., Havlík, P., Huppmann, D., Kiesewetter, G., Rafaj, P., Schoepp, W. \& Valin, H. A low energy demand scenario for meeting the $1.5^{\circ} \mathrm{C}$ target and sustainable development goals without negative emission technologies. Nature Energy 3, 515-527. www.doi.org/10.1038/s41560-018-0172-6 (2018).

25. Desing, H., Braun, G. \& Hischier, R. Ecological resource availability: a method to estimate resource budgets for a sustainable economy. Global Sustainability 3, 1-11. www.doi.org/10.1017/sus.2020. 26 (2020).

26. Ahman, M., Olsson, O., Vogl, V., Nykvist, B., Maltais, A., Nilsson, L., Hallding, K., Skanberg, K. \& Nilsson, M. Hydrogen steelmaking for a low carbon economy Report (Stockholm Environmental Institute, Lund University, 2018).

27. Gambhir, A. \& Tavoni, M. Direct Air Carbon Capture and Sequestration: How It Works and How It Could Contribute to Climate-Change Mitigation. One Earth 1, 405-409. www.doi.org/10.1016/j . oneear.2019.11.006 (2019).

28. Fasihi, M., Efimova, O. \& Breyer, C. Techno-economic assessment of CO2 direct air capture plants. Journal of Cleaner Production 224, 957-980. www. doi.org/10.1016/j . jclepro. 2019.03.086 (2019). 
29. Breyer, C., Fasihi, M. \& Aghahosseini, A. Carbon dioxide direct air capture for effective climate change mitigation based on renewable electricity: a new type of energy system sector coupling. Mitigation and Adaptation Strategies for Global Change 25, 43-65. www.doi.org/10.1007/s11027-019-9847-y (2019).

30. Deutz, S. \& Bardow, A. Life-cycle assessment of an industrial direct air capture process based on temperature-vacuum swing adsorption. Nature Energy 6, 203-213. www.doi.org/10.1038/s41560020-00771-9 (2021).

31. Joint Research Center. Transcontinental and global power grids Web Page. 2020. https://ses.jrc . ec.europa.eu/transcontinental-and-global-power-grids. 


\section{Supplementary materials to "How much energy storage can we afford? On the need for a sunflower society, aligning demand with renewable supply"}

Calculation code for LCA of energy storage options (in brightway2) as well as for the energy transition model including storage (in Matlab) can be found here: https://doi.org/10.5281/zenodo.5524262.

\section{S1 Additional figures}

Fig. S1 shows the evolution of transition dynamics to storage parameter. Increasing $\Delta t_{i}$ slows down the growth of the solar system and increasing $\phi$ inflicts more storage losses, therefore requiring a larger solar system.

Fig. S2 shows the range of probability of violation in dependence of transition time resulting from varying storage parameters and different technologies.

\section{S2 Energy costs for storage}

Energy storage options require both energy to build (embodied energy) as well as to operate (storage losses). These energy costs can be characterized by the parameters energy intensity EI and turnaround efficiency $\eta_{\text {turnarond }}$. The relevant parameters are defined and related as follows. Energy intensity of storage capacity (dimensionless):

$$
\begin{array}{rll}
E I & =\frac{E_{\text {embodied }}}{E_{\text {storage capacity }}} \\
E_{\text {embodied }} & \cdots & \text { embodied energy in electric energy equivalents } \\
E_{\text {storage capacity }} & \cdots & \text { nominal storage capacity in regard to stored output energy }
\end{array}
$$

Turnaround efficiency (excluding embodied energy input per output, as this is already accounted in EI):

$$
\begin{array}{rll}
\eta_{\text {turnaround }} & =\frac{E_{\mathrm{el}, \mathrm{out}}}{E_{\mathrm{el}, \mathrm{in}}} \\
E_{\mathrm{el}, \text { out }} & \ldots & \text { electric energy output (for an average charge cycle or over whole lifetime) } \\
E_{\mathrm{el}, \mathrm{in}} & \ldots & \text { operational electric energy input necessary to provide the output }
\end{array}
$$

Life cycle assessments often provide the fraction of embodied energy per output energy, which relates to $E I$ over the number of charge cycles $n_{\text {cycle }}$ and average discharge depth $D D_{\text {average,storage: }}$

$$
\begin{aligned}
E_{\text {el }, \text { out }} & =E_{\text {storage capacity }} \cdot D D_{\text {average,storage }} \cdot n_{\text {cycle }} \\
E I & =\frac{E_{\text {embodied }}}{E_{\text {el }, \text { out }}} \cdot D D_{\text {average,storage }} \cdot n_{\text {cycle }}
\end{aligned}
$$



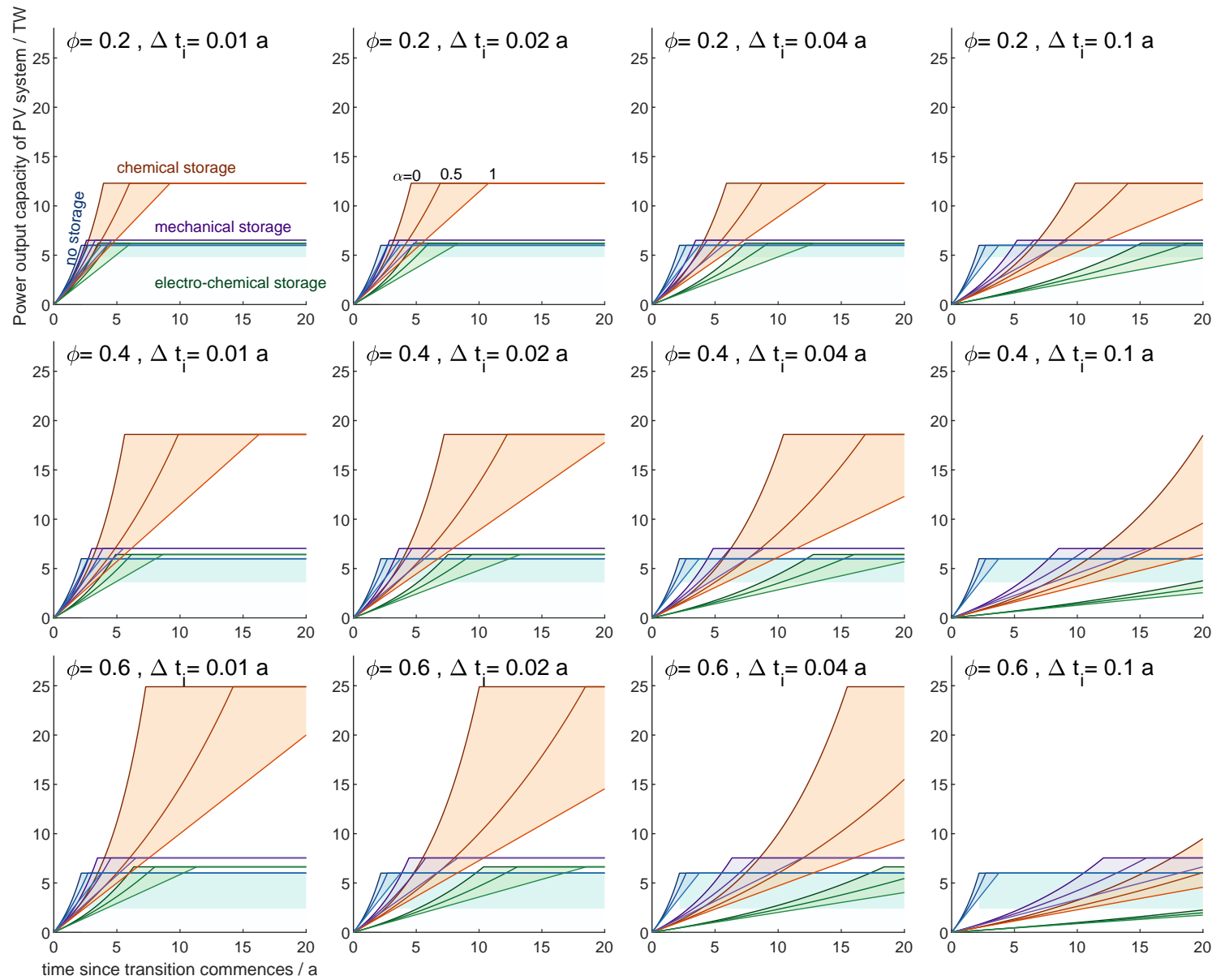

Figure S1: Transition dynamic for varying $\phi=[0.2,0.6]$ and $\Delta t_{i}=[0.01 \mathrm{a}, 0.1 \mathrm{a}$. Increasing $\phi$ increases the storage losses and therefore the required size of the PV system. Increasing $\Delta t_{i}$ instead slows down the growth and increases transition time.

In this paper, we analyse three main sets of storage technologies: Li-ion batteries, pumped hydro storage and synthetic fuels. Tab. S1 summarizes the energy performance of the considered storage systems.

\section{S2.1 Li-ion batteries}

Turnaround efficiency is estimated at $\eta_{\text {turnaround,Li-ion }}=0.85$ for all three different cell chemistry types (i. e. NMC111, NMC811 and NCA) [7, 11]. Storage losses are assumed to be equal at input and output, as most of the losses can be traced back to Ohm's resistance [Rolf?].

Energy intensity is calculated using the life cycle inventories from Crenna et al. [11] for all three cell chemistries and ecoinvent v.3.7.1 [12] as a background database. Embodied energy is calculated as the cumulative energy demand in electric energy equivalents (i. e. all contribution to CED converted into electric energy with state-of-the-art technologies, see [25]) per unit of storage capacity. Calculation is performed in brightway2 [32] and python code can be found online. Energy demand for Cobalt production is a main driver for total energy demand. Co datasets in ecoinvent v.3.7.1 are based on industry data, which are not public, however potentially more representative than Co in previous versions, which had been based on $\mathrm{Cu}$ production as a proxy.

\section{S2.2 Pumped hydro storage}

Turnaround efficiency is taken from ecoinvent v.2, which is based on a review of Swiss hydro power plants, including pumped hydro installations [14]. New installations may have turnaround efficiencies up to $85 \%$ 

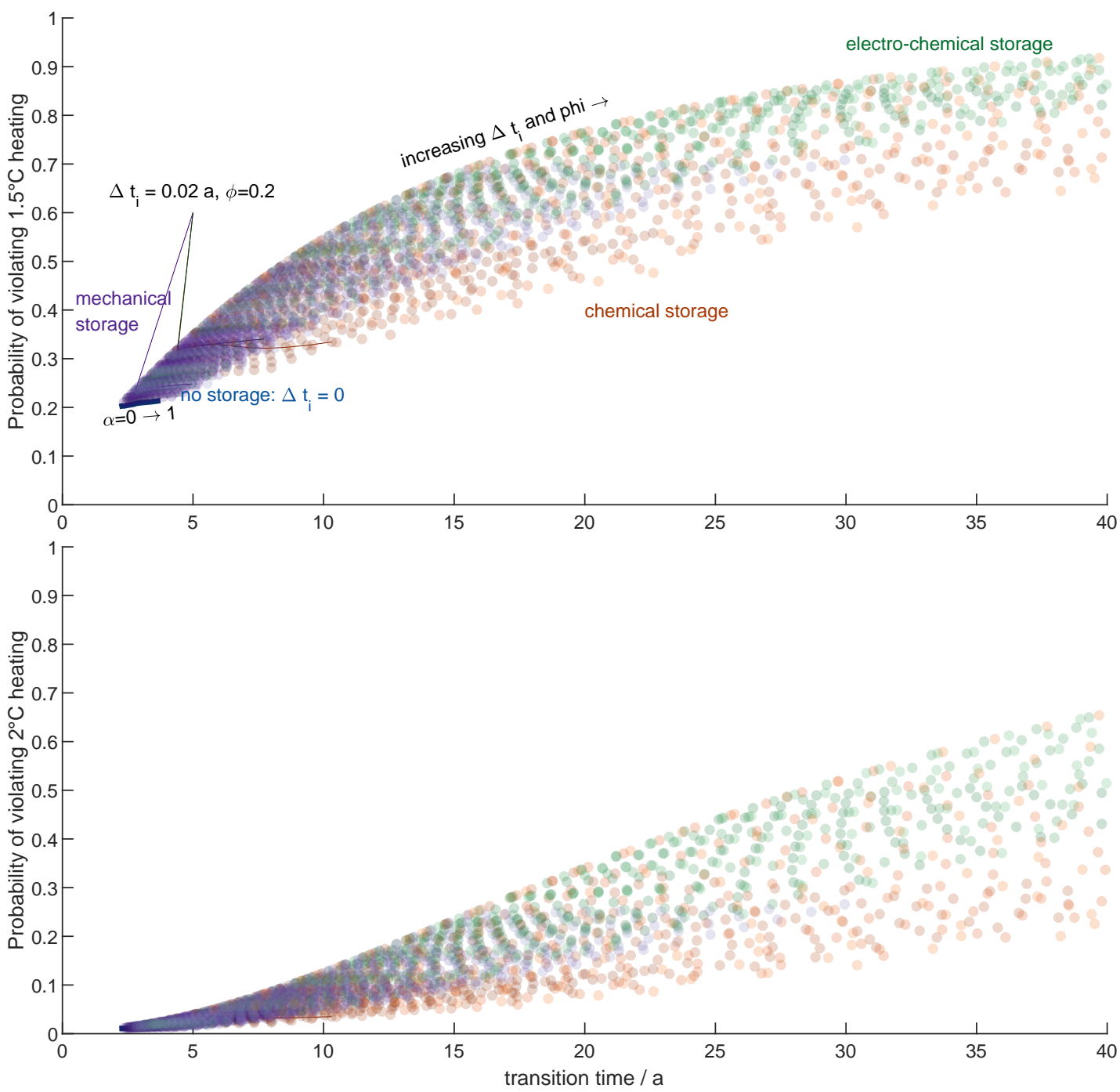

Figure S2: Cumulative $\mathrm{CO}_{2}$ emissions until the transition is completed (transition time on x-axis) correlate to the probability of violating $1.5^{\circ} \mathrm{C}$ (upper panel) and $2{ }^{\circ} \mathrm{C}$ (lower panel). Blue line indicates the probabilities and transition times for a transition without storage [4]. Both transition time and probability of violation increase with $\phi$ and $\Delta t_{i}$, however differently depending on storage technology groups: mechanical storage (violet), chemical storage (orange) and electro-chemical storage (green). 


\begin{tabular}{lccccc}
\hline storage technology & $\begin{array}{c}\text { turnaround } \\
\text { efficiency }\end{array}$ & $\begin{array}{c}\text { input } \\
\text { efficiency }\end{array}$ & $\begin{array}{c}\text { output } \\
\text { efficiency }\end{array}$ & $\begin{array}{c}\text { energy } \\
\text { intensity }\end{array}$ & Source \\
\hline Li-Ion battery: NMC111 & 0.85 & 0.92 & 0.92 & 457 & {$[11,12]$} \\
Li-Ion battery: NMC811 & 0.85 & 0.92 & 0.92 & 323 & {$[11,12]$} \\
Li-Ion battery: NCA & 0.85 & 0.92 & 0.92 & 339 & {$[11,12]$} \\
pumped hydro storage & 0.7 & 0.8 & 0.87 & 81 & {$[12]$} \\
pumped hydro storage, & 0.7 & 0.8 & 0.87 & 90 & {$[12]$} \\
$\begin{array}{l}\text { increased lifetime } \\
\text { synthetic methane }\end{array}$ & 0.16 & 0.41 & 0.4 & 63 & {$[12,13]$} \\
(PEM + DAC) & & & & & \\
\hline
\end{tabular}

Table S1: Energy performance of selected storage technologies. Background database for LCA calculations is ecoinvent v.3.7.1 [12].

$[7,9,33]$. Turbine efficiency (output) is usually higher than pumping efficiency (input), therefore we assume $\eta_{\text {output }}=0.87$ and $\eta_{\text {input }}=0.8$

The energy intensity is calculated with Equation 4 from embodied energy over energy stored over its lifetime, which can be calculated from ecoinvent $[12,14]$. Calculation code in brightway2 can be found online.

\section{S2.3 Synthetic methane}

Turnaround efficiency, output efficiency and energy intensity are calculated from the life cycle inventory modelling of Zhang et al. [13]. As for pumped hydro storage, EI is calculated with Equation 4. Calculation code in brightway2 can be found online.

\section{S3 Storage demand}

Storage needs to be able to provide the required demand throughout a chosen independence time $\Delta t_{\text {independence }}$. Storage capacity $E_{\text {storage capacity }}$ therefore needs to be:

$$
E_{\text {storage capacity }}=\Delta t_{\text {independence }} \cdot \frac{P_{\text {demand,required }}}{\eta_{\text {out }}}
$$

Storage losses depend on the turnaround efficiency $\eta_{\text {storage }}$ and the fraction of the annual demand $\phi$, which is actually stored. This fraction has two components: first, daily storage, which is a function of how well the annual average daily demand follows solar supply. To estimate the maximum fraction of annual average daily harvest that needs to be stored, we approximate the irradiation profile over the course of a day as a cosinus function:

$$
P_{\mathrm{PV}}(\psi)= \begin{cases}-P_{\mathrm{PV}, \max } \cos \psi & \text { if } \quad-\cos \psi \leq 0 \\ 0 & \text { else }\end{cases}
$$

where $\psi=0$ corresponds to midnight ( 0 a.m.), $\psi=\pi$ to midday (12a.m., see figure S3).

The average solar power over $24 \mathrm{~h}$ is:

$$
\bar{P}_{\mathrm{PV}}=\int_{\frac{\pi}{2}}^{\frac{3 \pi}{2}} P_{\mathrm{PV}}(\psi) d \psi=\frac{P_{\mathrm{PV}, \max }}{\pi}
$$

If we assume the demand to be constant over the day, any power in excess of the average power output 


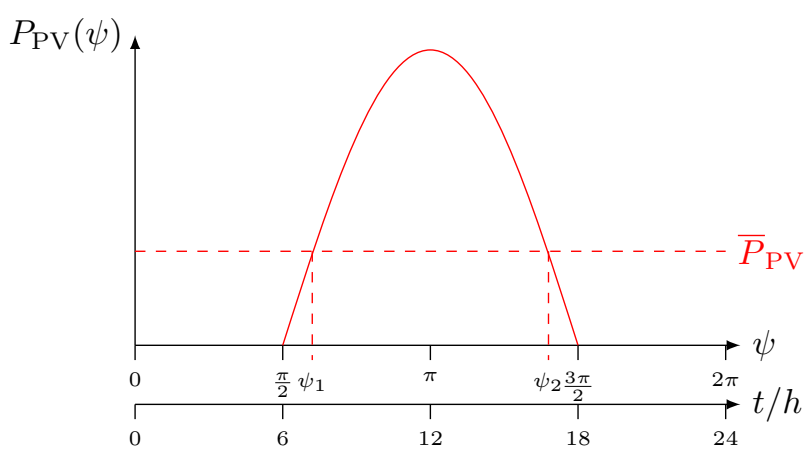

Figure S3: For the approximation of maximum daily storage demand: yearly average solar power profile (solid line) matching constant demand $\left(\bar{P}_{\mathrm{PV}}\right.$, dashed line).

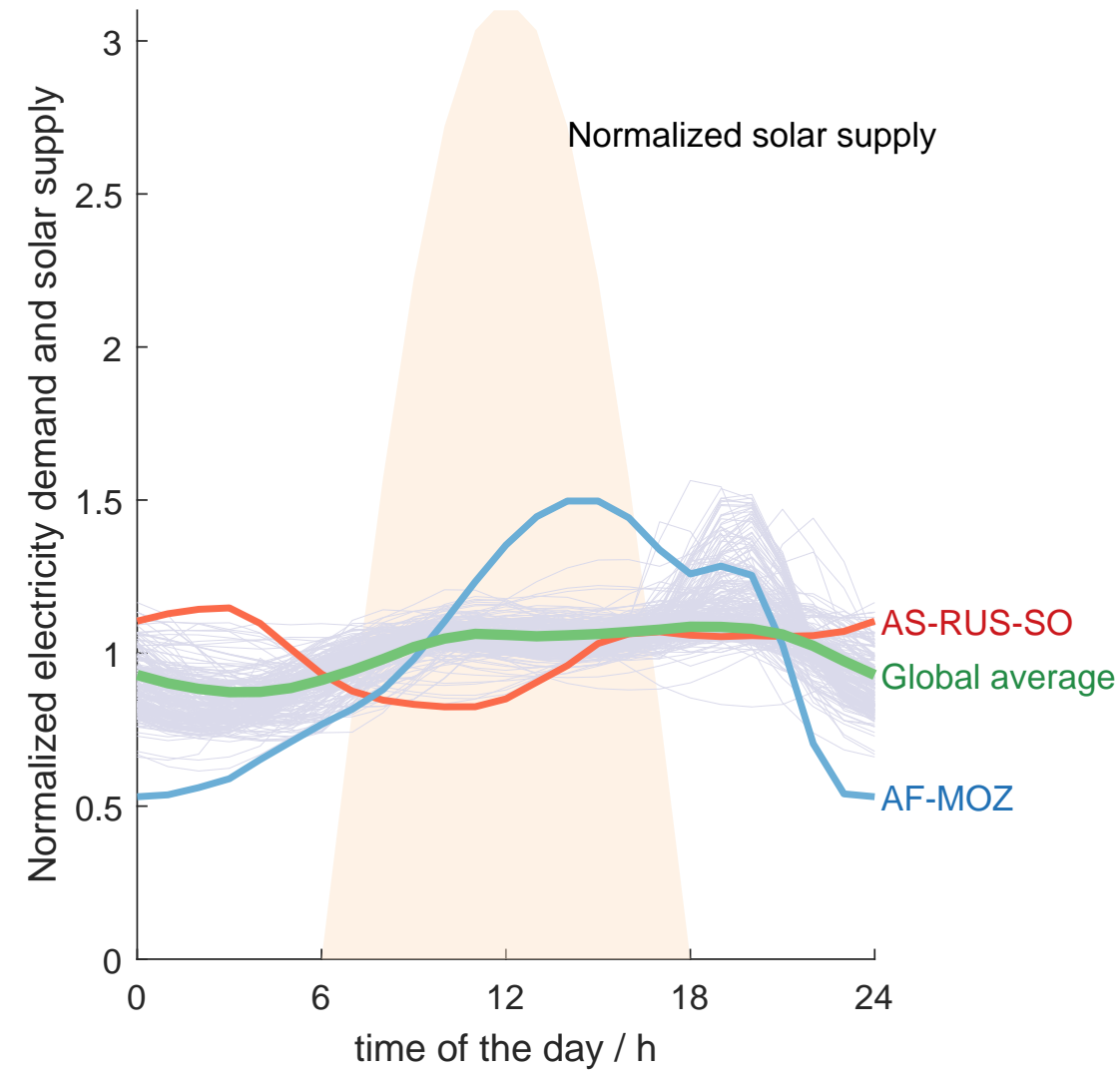

Figure S4: Annual average electricity demand profiles for 270 world regions in comparison to normalized solar supply. All lines are normalized so that the area under each curve is equal. Global average highlighted in green; Mozambique (AF-MOZ [19]) has the lowest storage demand (blue), while in the south of Russia (AS-RUS-SO [19]) demand is most unaligned to solar supply, requiring most storage (red). 
would need to be stored.

$$
\begin{aligned}
E_{\text {daily storage,max }} & =\int_{\psi_{1}}^{\psi_{2}} P_{\mathrm{PV}}(\psi) d \psi-\bar{P}_{\mathrm{PV}}\left(\psi_{2}-\psi_{1}\right) \\
E_{\mathrm{PV}, \text { daily }} & =\int_{\frac{\pi}{2}}^{\frac{3 \pi}{2}} P_{\mathrm{PV}}(\psi) d \psi \\
\phi_{\text {daily }} & =\frac{E_{\text {daily storage,max }}}{E_{\mathrm{PV}, \text { daily }}}=0.587
\end{aligned}
$$

The independence time to store daily variations is

$$
\Delta t_{i}=1-\frac{\psi_{2}-\psi_{1}}{2 \pi}=14.5 \mathrm{~h}
$$

Demand profiles of current electricity demand across the globe show a slightly higher demand during the day than during the night. Therefore the fraction of daily demand stored is smaller. Analysing data for electricity demand in $2015[19]^{2}$ yields $\phi_{\text {daily,global }}=0.54$ for the global average of daily demand needing storage (see Matlab code: data from [19] needs to be shifted by time zones to local time, which is assumed to be approximately solar time; and Fig. S4). Mozambique has the demand profile, which is most aligned to solar supply, thus requiring the lowest $\phi_{\text {daily, } \mathrm{MOZ}}=0.45$. In contrast, the southern region of Russia has the highest demand for storage with $\phi_{\text {daily,RUS-SO }}=0.59$. This is even higher than for the constant demand (Equation 10), as here demand is lower during the day and higher in the night. Note, that these demand profiles only concern electricity and do not reflect demand for mobility or fuels.

\section{S4 Transition model}

This transition model is based on previous work [4] and implemented in Matlab R2018a.

Power demand by society is assumed constant at $P_{\text {demand }}=6 \mathrm{TW}$ during the transition, which is approximately the current size of the non-renewable energy system [4, 5, 34]. Carbon emissions other than from the fossil energy system are considered to be reduced to (net-)zero during the transition (i. e. land use change and industry).

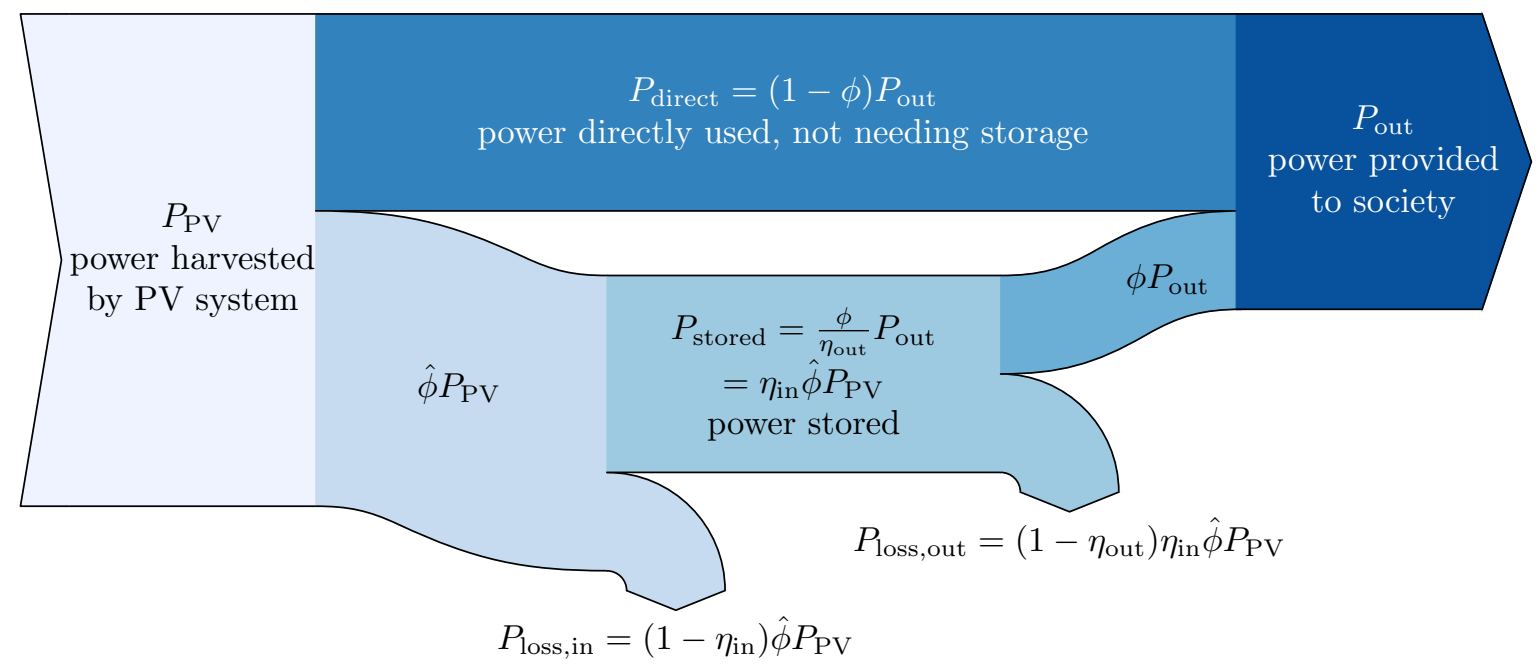

Figure S5: Energy flow from solar harvest $\left(P_{\mathrm{PV}}\right)$ through storage to supply to society $\left(P_{\text {out }}\right)$.

The energy payback time for the newly installed solar and storage capacities needs to be adjusted from $E P B T_{\mathrm{PV}}$ by both the energy intensity of storage and storage losses. It is determined as follows (see ${ }^{2}$ Data can be accessed here: https://dataverse.harvard.edu/file.xhtml?persistentId=doi:10.7910/DVN/CBYXBY/
HXZGSB\&version=6.2 
Fig. S5):

$$
\begin{aligned}
P_{\mathrm{PV}} & =(1-\phi) P_{\text {out }}+\frac{\phi}{\eta} P_{\text {out }}=P_{\text {out }}\left(1+\phi\left(\frac{1}{\eta}-1\right)\right) \\
\eta & =\eta_{\text {in }} \cdot \eta_{\text {out }} \\
E P B T & =\frac{E_{\text {embodied }}}{P_{\text {out }}}=\frac{E_{\mathrm{PV}, \text { embodied }}+E_{\text {storage, embodied }}}{P_{\mathrm{PV}}-P_{\text {storage }, \text { loss }}} \\
& =\frac{P_{\mathrm{PV}} E P B T_{\mathrm{PV}}+E I E_{\text {storage,capacity }}}{P_{\text {out }}} \\
& =\frac{1}{P_{\text {out }}}\left(P_{\text {out }}\left(1+\phi\left(\frac{1}{\eta}-1\right)\right) E P B T_{\mathrm{PV}}+\Delta t_{i} \cdot E I P_{\text {stored }}\right) \\
& =\left(1+\phi\left(\frac{1}{\eta}-1\right)\right) E P B T_{\mathrm{PV}}+\Delta t_{i} \cdot E I \frac{\phi}{\eta_{\text {out }}}
\end{aligned}
$$

During the transition, only the fraction of replaced fossil energy would need to be stored; therefore Equation 14 can be adjusted to reduce the storage losses during the transition:

$$
E P B T=\underbrace{\left(1+\alpha \phi\left(\frac{1}{\eta}-1\right)\right)}_{\text {storage loss }} E P B T_{\mathrm{PV}}+\underbrace{\Delta t_{i} \cdot E I \frac{\phi}{\eta_{\text {out }}}}_{\text {embodied energy of storage }}
$$

If during the transition fossil replacements are zero $(\alpha=0)$, no storage losses would occur during the transition but only afterwards. In this case, the EPBT is enlarged only by embodied energy of storage. In contrast if fossil replacements are $\alpha=1$, storage losses further reduce the available power to grow the solar system and increase EPBT even more.

The transition is completed, when the solar engine is big enough to supply the demand by society. In case no storage is needed, this is the case as soon as $P_{\mathrm{PV}}=P_{\text {demand }}$. In case of storage, the required size of the solar system depends on storage technology and stored fraction, as it has to provide the storage losses in addition (see Fig. S5).

$$
\begin{aligned}
P_{\mathrm{PV}, \text { required }} & =P_{\text {demand }}+P_{\text {storage loss }} \\
& =P_{\text {demand }}\left(1+\phi\left(\frac{1}{\eta}-1\right)\right)
\end{aligned}
$$

\section{References}

32. Mutel, C. Brightway: An open source framework for Life Cycle Assessment. The Journal of Open Source Software 2. www . doi.org/10.21105/joss.00236 (2017).

33. Grote, K. \& Feldhusen, J. Dubbel - Taschenbuch für den Maschinenbau 21st ed. (Springer, 2005).

34. International Energy Agency. Energy Balance for the World Web Page. 2018. https : //www . iea.org/Sankey/\%5C\#?c=World\&s=Balance. 